\title{
Exotic Rickettsiae in Ixodes ricinus: fact or artifact?
}

\author{
Ellen Tijsse-Klasen', Manoj Fonville1, Leo van Overbeek², Johan HJ Reimerink ${ }^{3}$ and Hein Sprong ${ }^{* 1}$
}

\begin{abstract}
Several pathogenic Rickettsia species can be transmitted via Ixodes ricinus ticks to humans and animals. Surveys of I. ricinus for the presence of Rickettsiae using part of its $16 \mathrm{~S}$ rRNA gene yield a plethora of new and different Rickettsia sequences. Interpreting these data is sometimes difficult and presenting these findings as new or potentially pathogenic Rickettsiae should be done with caution: a recent report suggested presence of a known human pathogen, $R$. australis, in questing I. ricinus ticks in Europe. A refined analysis of these results revealed that $R$. helvetica was most likely to be misinterpreted as $R$. australis. Evidence in the literature is accumulating that rickettsial DNA sequences found in tick lysates can also be derived from other sources than viable, pathogenic Rickettsiae. For example, from endosymbionts, environmental contamination or even horizontal gene transfer.
\end{abstract}

\section{Findings}

Hard ticks (Ixodidae) are the main vectors of the spotted fever Rickettsiae in humans, a group of diseases that is be caused by approximately 20 different Rickettsia species of which one-third circulate in Europe [1]. Recently, van Overbeek and colleagues reported the presence of Rickettsia australis in I. ricinus ticks [2]. They successfully amplified the 16S rRNA gene from DNA extracts from ticks derived from three natural areas in the Netherlands. Sequences of some fragments matched best with $R$. australis (99\% similarity), and therefore the authors concluded that they identified $R$. australis. They found 28 ticks positive for the sequence, and reported that the prevalence of $R$. australis varied between 6.7 and 33\% in the investigated areas. This finding struck us as remarkable as it would be the first description of this pathogen in Europe. $R$. australis is the etiologic agent of Queensland tick typhus, a disease that normally occurs along the eastern coast of Australia, including Queensland. Clinical features that may be present include fever, headache, myalgia and an eschar at the site of the tick bite. A maculopapular or vesicular skin rash is frequently noted. Patients usually make an uncomplicated recovery, but severe to fatal outcomes have been attributed to R. australis infection as well [3]. Thus, the presence of $R$. aus-

\footnotetext{
* Correspondence: Hein.Sprong@rivm.nl

${ }^{1}$ Laboratory for Zoonoses and Environmental Microbiology, National Institute for Public Health and Environment (RIVM), Antonie van Leeuwenhoeklaan 9, P.O. Box 1, Bilthoven, the Netherlands

Full list of author information is available at the end of the article
}

tralis in Europe could have significant public health consequences.

This publication was noted by Lyme patients' associations in The Netherlands and they promptly discussed these findings on their websites (http://www.borreliose.nl/; http://www.lymevereniging.nl/). At our institute, ticks from various sources are routinely tested for potential pathogens [4-7], but during the last decade, we never detected $R$. australis-positive ticks. R. helvetica, on the other hand, was found in ticks from every studied location with a prevalence varying from 6 to $67 \%(\sim 6000$ ticks). This raised the question how this obvious discrepancy between our results could be explained.

We therefore re-examined the original sequence data of the van Overbeek study, which covered the last $450 \mathrm{bp}$ of the 16S rRNA gene by comparison to sequences of $R$. helvetica [GenBank:L36212] and $R$. australis [GenBank:L36101] published in GenBank (Figure 1). These sequences contained 4 and 7 nucleotide changes compared to the matching target sequences of $R$. helvetica and $R$. australis, respectively. Next, a fraction of the DNA samples of ticks from their study were re-examined with our PCR-amplification protocol followed by Reverse Line Blot (RLB) as described earlier [7]. In theory, our PCR protocol using generic 16S rRNA primers for Rickettsiae would be able to amplify $R$. australis DNA (not shown). The PCR products of these samples hybridized with the $R$. helvetica RLB probe. The PCR-products were sequenced on both strands, and turned out to be $100 \%$ identical to the published $R$. helvetica ([GenBank:L36212]; Figure 1). For confirmation, part of the 


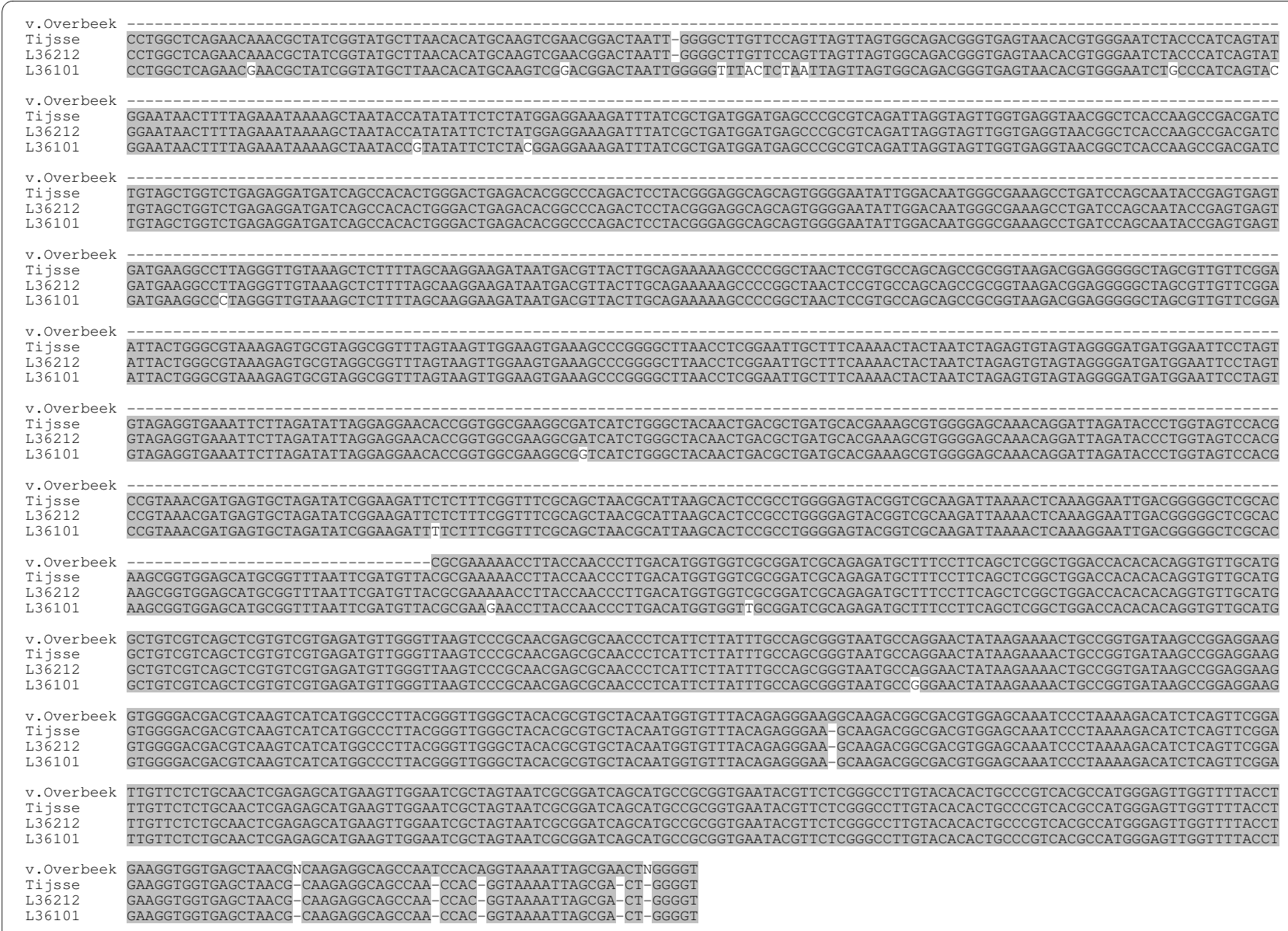

Figure 1 Comparison of sequences from tick lysates with reference sequence. 16S rRNA gene sequences from Genbank (R. australis: $\underline{L} 36101, R$. helvetica: $\underline{L}$ 36212) were aligned with sequences from the Van Overbeek study (v.Overbeek) and with the sequence we obtained from their samples (Tijsse).

ompB gene was amplified (729 bp) as an independent marker and sequenced. The sequence was $100 \%$ identical to the corresponding $\operatorname{omp} B$ gene sequence of $R$. helvetica [GenBank:AF123725] and was only $38.9 \%$ similar to $R$. australis [GenBank:AF123709]. Thus, we could not detect $R$. australis in the DNA samples of the previous study. Instead, we have strong indications that $R$. helvetica was misidentified as $R$. australis because of a combination of sequencing errors and usage of a limited set of reference sequences.

\section{Competing interests}

The authors declare that they have no competing interests.

\section{Authors' contributions}

ETK and HS performed (bioinformatics) analyses. MF and ETK collected new data. ETK and JHJR wrote the initial draft. HS wrote the final manuscript. LO provided tick lysates and sequence data. JHJR and HS acquired funding. All authors read and approved the final manuscript.

\section{Acknowledgements}

We thank Marion Koopmans (RIVM) for critically reading the manuscripts and helpful comments.

\section{Author Details}

'Laboratory for Zoonoses and Environmental Microbiology, National Institute for Public Health and Environment (RIVM), Antonie van Leeuwenhoeklaan 9, P.O. Box 1, Bilthoven, the Netherlands, ${ }^{2}$ Wageningen University and Research Centre, Plant Sciences Group, PB, Wageningen, The Netherlands and

${ }^{3}$ Laboratory for Infectious Diseases and Screening, National Institute for Public Health and Environment (RIVM), Antonie van Leeuwenhoeklaan 9, P.O. Box 1, Bilthoven, The Netherlands

Received: 18 June 2010 Accepted: 22 June 2010

Published: 22 June 2010

\section{References}

1. Blanco JR, Oteo JA: Rickettsiosis in Europe. Ann N Y Acad Sci 2006 , 1078:26-33.

2. van Overbeek L, Gassner F, van der Plas CL, Kastelein P, Nunes-da Rocha U, Takken W: Diversity of Ixodes ricinus tick-associated bacterial communities from different forests. FEMS Microbiol Ecol 2008, 66:72-84

3. McBride WJ, Hanson JP, Miller R, Wenck D: Severe spotted fever group rickettsiosis, Australia. Emerg Infect Dis 2007, 13:1742-1744.

4. Wielinga PR, Gaasenbeek C, Fonville M, de Boer A, de Vries A, Dimmers W, Akkerhuis Op Jagers G, Schouls LM, Borgsteede F, van der Giessen JW: Longitudinal analysis of tick densities and Borrelia, Anaplasma, and Ehrlichia infections of Ixodes ricinus ticks in different habitat areas in The Netherlands. Appl Environ Microbiol 2006, 72:7594-7601.

5. Sprong $\mathrm{H}$, Wielinga PR, Fonville $\mathrm{M}$, Reusken C, Brandenburg AH, Borgsteede F, Gaasenbeek C, van der Giessen JW: Ixodes ricinus ticks are 
reservoir hosts for Rickettsia helvetica and potentially carry flea-borne Rickettsia species. Parasit Vectors 2009, 2:41.

6. Wielinga PR, Fonville M, Sprong H, Gaasenbeek C, Borgsteede F, Giessen JW: Persistent Detection of Babesia EU1 and Babesia microti in Ixodes ricinus in The Netherlands During a 5-Year Surveillance: 2003-2007. Vector Borne Zoonotic Dis 2008.

7. Tijsse E, Fonville M, Reimerink JH, Spitzen-van der Sluijs A, Sprong H: Role of sand lizards in the ecology of Lyme and other tick-borne diseases in the Netherlands. Parasit Vectors 3:42.

doi: 10.1186/1756-3305-3-54

Cite this article as: Tijsse-Klasen et al., Exotic Rickettsiae in Ixodes ricinus:

fact or artifact? Parasites \& Vectors 2010, 3:54
Submit your next manuscript to BioMed Central and take full advantage of:

- Convenient online submission

- Thorough peer review

- No space constraints or color figure charges

- Immediate publication on acceptance

- Inclusion in PubMed, CAS, Scopus and Google Scholar

- Research which is freely available for redistribution

Submit your manuscript at www.biomedcentral.com/submit
() BioMed Central 